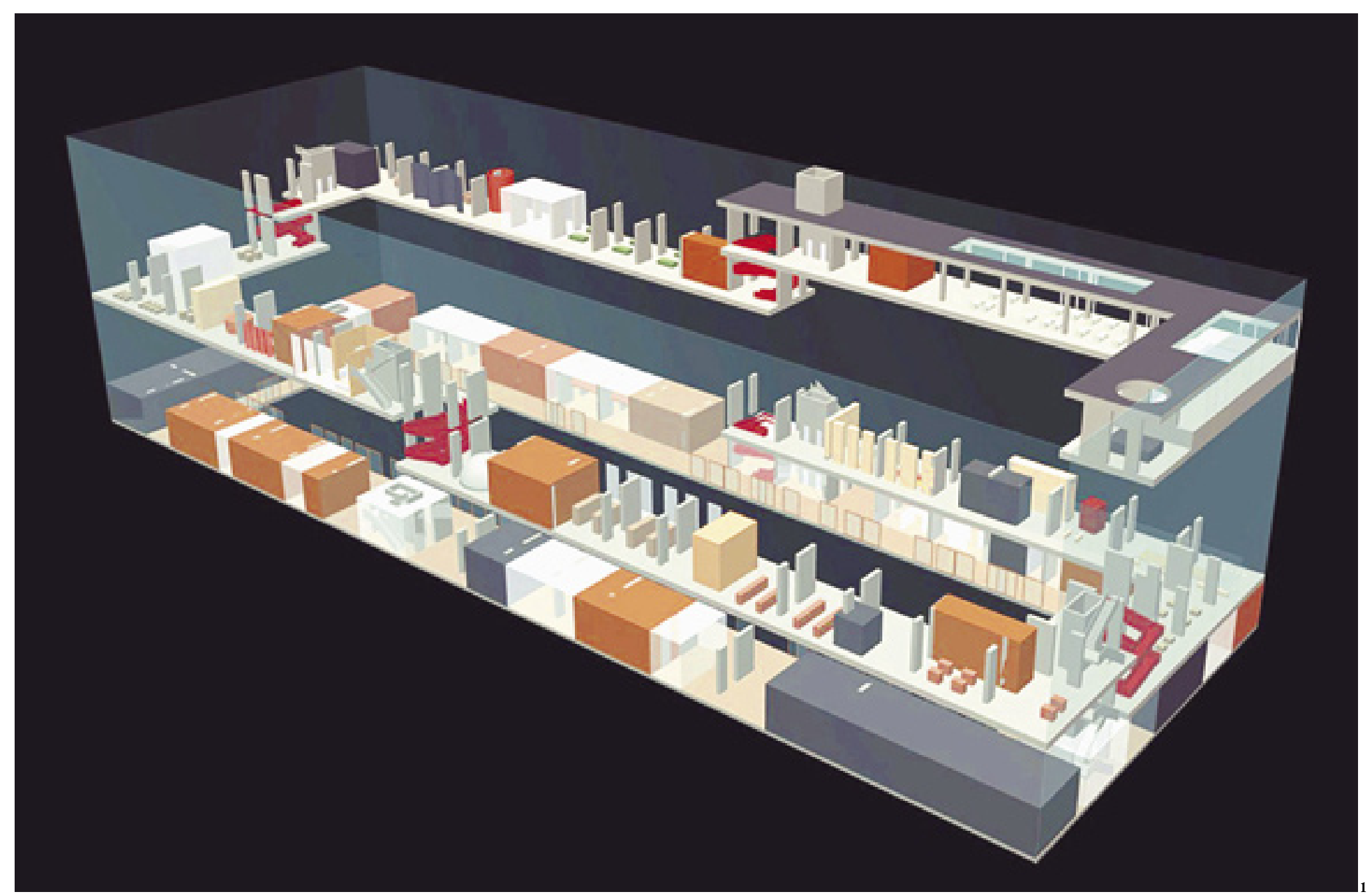

\section{Alejandro Morales}

Pareciera una paradoja pretender hacer una arquitectura propia de una región, convocando a cerca de 900 propuestas de todo el mundo. Pero Oriente, mediante la proliferación de concursos arquitectónicos, asume como problema global las necesidades propias de un lugar específico. Este proyecto galardonado es resultado de esta mirada renovada y extranjera al tema de las politicas habitacionales por parte de un gobierno municipal.

Palabras clave: Concursos de arquitectura, edificio de viviendas.

It seems paradoxical to commission nearly 900 proposals from all around the globe in order to create a regionally identifiable architecture. East countries, however, by means of a large number of architectural competitions, assumes as a global problem the needs of a specific place. This award-winning project is the result of such a renewed and foreign outlook on the housing policies of a local government.

\title{
Concurso Aomori, Japón
}

En los últimos años han surgido numerosos concursos internacionales de arquitectura en el Oriente: Japón, Korea, Singapur, China... invitaciones abiertas a los arquitectos del mundo, que pretenden por un lado obtener una respuesta multicultural a los problemas -dando por hecho una realidad globalizada- y que por otro lado actúan como carta de presentación ante el mundo de las distintas localidades.

Oriente, a través de su política de Concursos Internacionales, promueve el intercambio $y$ renovación profesional, hace posible el ejercicio de la profesión más allá de las fronteras habituales e impone una actitud muy democrática: son las ideas las que concursan, y no el tamaño de la oficina, los $\mathrm{m}^{2}$ construidos, o lo que sea que restrinja o catalogue a los distintos profesionales participantes. Sin prejuicios.

\section{Aomori City}

Aomori es una ciudad costera, la más nortina de la gran isla Honshu, con un clima muy extremo, un largo invierno con fuertes nevadas (prácticamente 5 meses) e inserta en un paisaje natural que es considerado uno de los más bellos del Japón. Es una ciudad de mediana escala en proceso de expansión, con una población cercana a los

\subsection{0 habitantes.}

El gobierno de la ciudad de Aomori se ha propuesto un Plan de Desarrollo Urbano a largo plazo, el que han denominado "Una ciudad para el siglo 21- un entorno natural".

Los dos grandes objetivos planteados dentro del plan son los siguientes:

1. Una ciudad más tolerante al invierno. La cantidad y duración de las nevadas hacen prioritario buscar nuevas formas de habitar, que hagan más confortable la vida en Aomori.

2. Una ciudad más compacta. Evitar la expansión descontrolada de la periferia de la ciudad, que va desplazando el paisaje natural, planteando una revitalización del centro histórico.

Dentro de este contexto el gobierno de la ciudad llamó a un Concurso Internacional de Ideas, al que denominaron Northern Style Housing Complex in Aomori. El tema del concurso era proyectar un nuevo tipo de vivienda urbana, para áreas céntricas, que resolviera los dos grandes temas planteados anteriormente. El programa solicitado incluía unas 200 unidades de vivienda, que debían complementarse con diversos programas comunitarios y algún área comercial. Un sitio de $13.000 \mathrm{~m}^{2}$ aprox. inserto en un área céntrica bastante densa. 

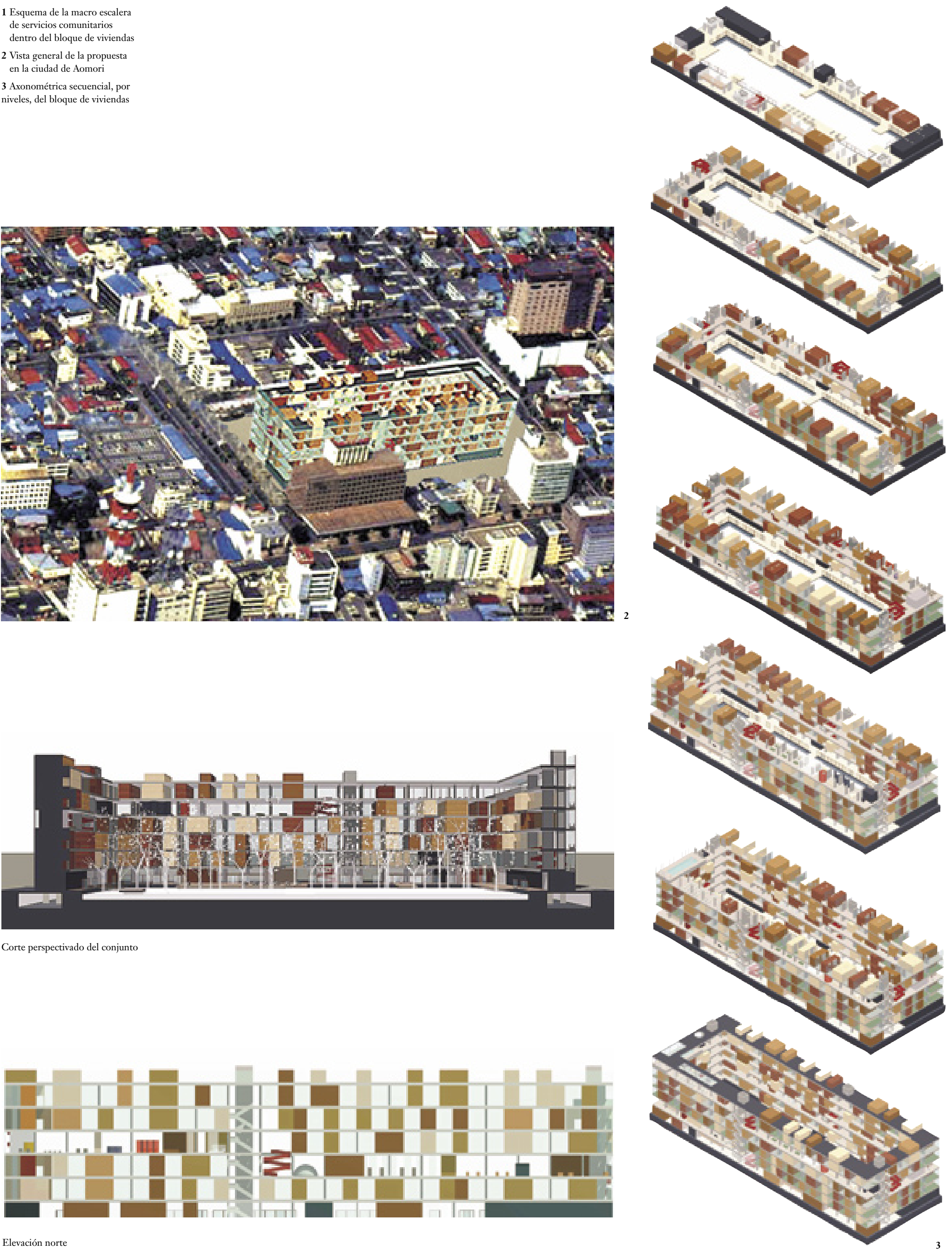

Elevación norte 


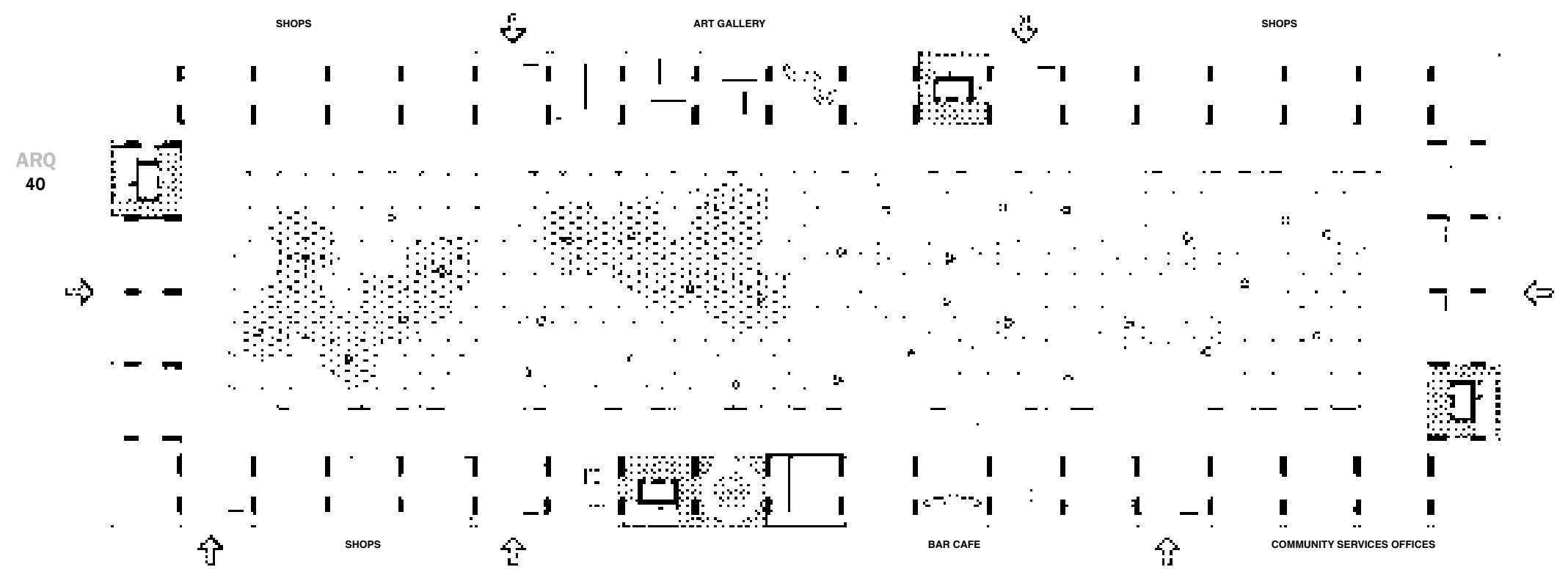

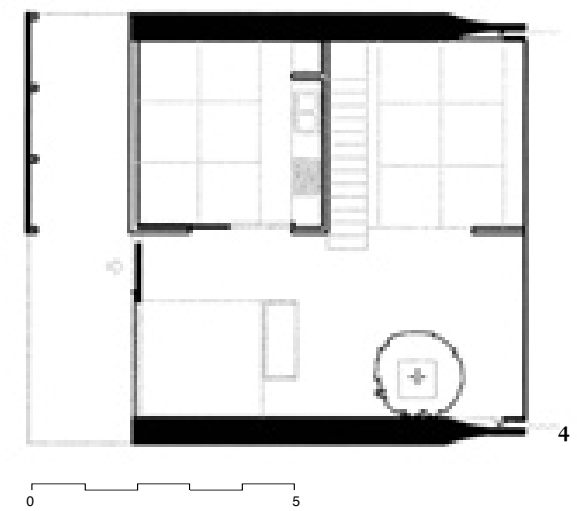

El jurado del concurso estaba presidido por los arquitectos Jean Nouvel y Tadao Ando. Se recibieron 897 propuestas de todo el mundo; finalmente se determinaron 7 proyectos finalistas, y se entregaron algunos premios especiales del Jurado, que no estando previamente considerados, hacían reconocimiento a una gran cantidad de buenos proyectos presentados ${ }^{1}$.

\section{Una propuesta}

El tipo de vivienda a desarrollar quedó absolutamente abierto, pero en el fondo se buscaba un modelo que pudiera competir con la vivienda aislada de los suburbios. A mi entender, en las ciudades menores los habitantes tienden a preferir modelos de vivienda más próximos a la casa aislada que al tipo de edificio de departamentos; eso lo podemos constatar en las ciudades de provincia chilenas, donde los edificios grandes y altos
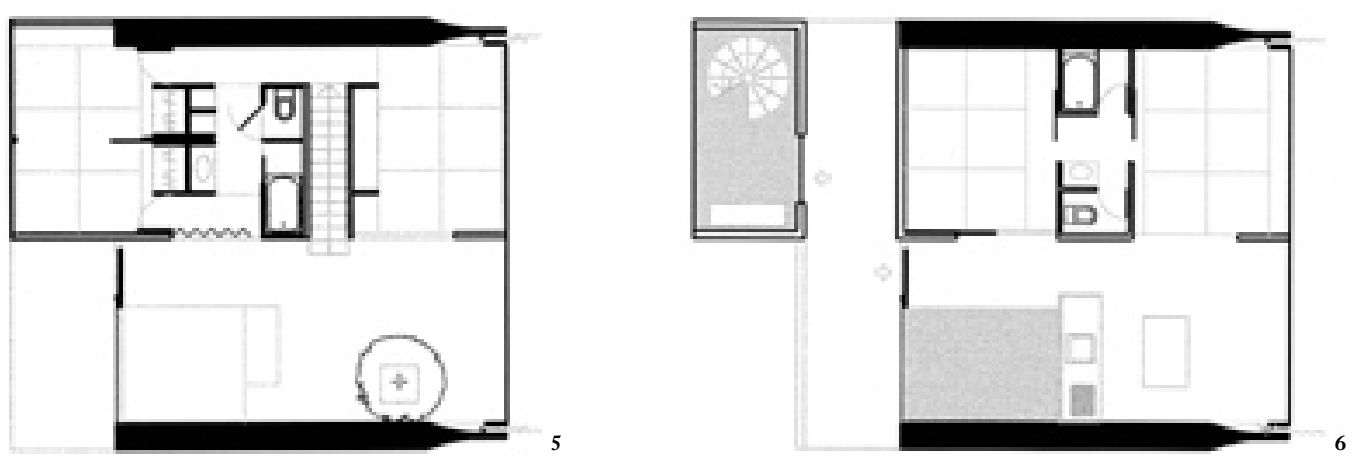

son realmente una excepción. En las ciudades menores la verticalidad es una idea incipiente: se habita horizontalmente, más allá de cuán denso sea el entorno construido.

La condición de ciudad de tamaño medio en proceso de crecimiento se muestra en Aomori en un área central que presenta algunos edificios de escala metropolitana inmersos en una marea de incontables edificios y casas pequeñas de diferentes calidades materiales y variada data: no hay mediación entre ambas escalas.

Mi propuesta para el concurso asume que este conflicto de escala es un problema a enfrentar. ¿Cómo crear un edificio que dialogue con un presente provinciano y a su vez se proyecte hacia un futuro metropolitano?

Reconocer que los habitantes de Aomori prefieren la tipología de casa aislada llevó a plantear un tipo de vivienda mixto, que combina ciertas condiciones o percepciones de una casa aislada en tierra con la necesidad de crear un edificio en altura. Se plantea una solución intermedia entre el habitar horizontal y el habitar en altura; la propuesta propone una tipología mixta muy similar a los Inmueble Villas de Le Corbusier, una suerte de manzana vertical de viviendas.

Para definir la condición de "horizontalidad" buscada se recurrió a la noción de jardín, entendiéndolo como un espacio de la vivienda de fuerte carga sensorial y con una impronta programática imprecisa, como un espacio que media el interior con el mundo exterior.

Esta condición de jardín se trasladó a la altura a través de lo que se denominó el "salón jardín" (garden room), un espacio de doble altura vidriado, a la manera de un invernadero, que ocupa una superficie igual a la vivienda misma (su negativo), actúa como una "ventana 


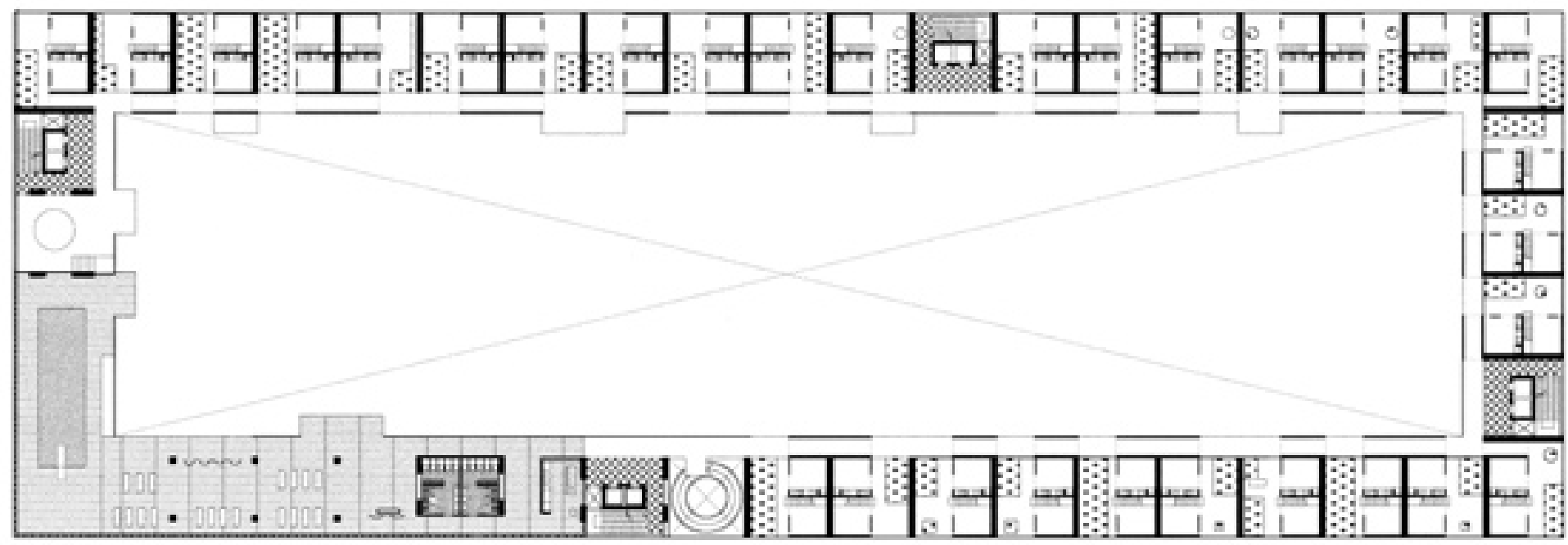

Planta bloque de viviendas, nivel +28.00

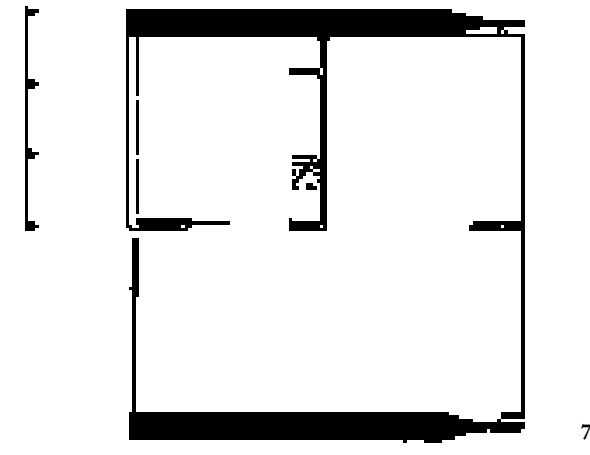

tridimensional" frente al paisaje, y cuya función es indefinida y variable. El salón jardín es el lugar para lo no programado, el lugar para dialogar con el entorno, y la respuesta al habitar en invierno con una fuerte sensación de exterior.

La solución final del proyecto se plantea como un edificio compuesto de pequeños edificios aislados, una estructura de soporte de hormigón armado, modulada de manera muy repetitiva, que conforman los denominados "sitios tridimensionales", sobre los cuales se han de montar viviendas de construcción ligera. Por cada lleno (vivienda) hay un vacío (sala jardín), lo que genera una elevación del edificio permeable al entorno. Las losas de cada nivel se plantearon como losas de vigas invertidas, lo que dio lugar a un espacio de $50 \mathrm{~cm}$ de profundidad bajo el nivel de cada piso, espacio para disponer elementos técnicos y de bodegaje, y en el área de los salones
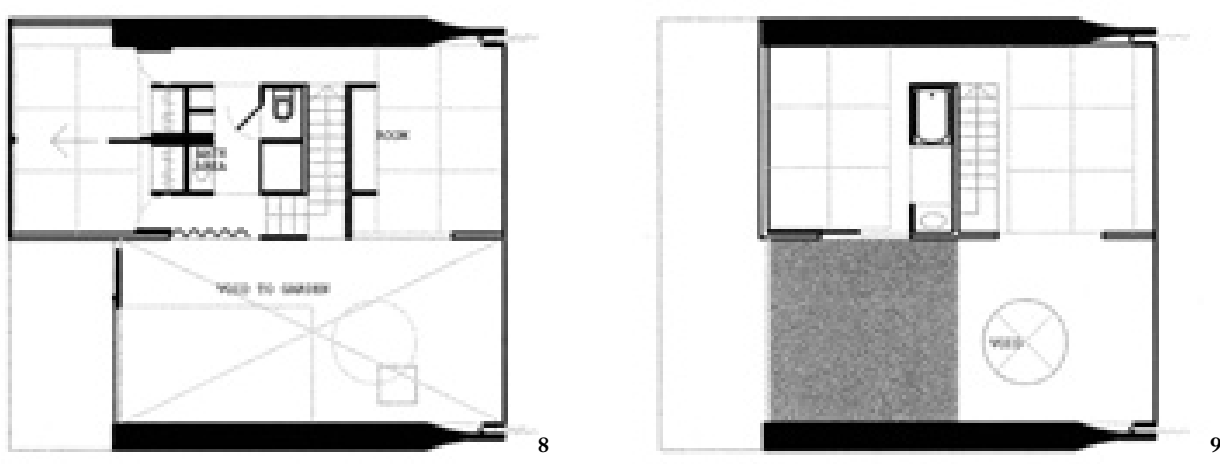

jardín, la posibilidad de tener tierra para plantar, colocar una pileta, permitir ciertas actitudes y hechos relativos a "la tierra".

Los programas comunitarios incluidos en el proyecto se dispusieron en una configuración ascendente a través del edificio, a la manera de una "mega-escalera": una secuencia lineal de programas alternados, que permite recorrer los distintos niveles del edificio de una manera "horizontalizada", como alternativa a las conexiones verticales, escaleras y ascensores. La disposición de los programas comunitarios permiten romper el ritmo de las elevaciones, agregan una segunda lectura y, muy importante, proponen una totalidad no zonificada, alternando vivienda con otras actividades de una manera aparentemente azarosa.

El edificio contiene en su centro un gran vacío, un área verde, que fue planteada como lo más natural posible (bajo ella no hay subterráneos). Ello permite plantar grandes árboles en un espacio dominado por lo natural: es el lugar para que las diferentes estaciones del año muestren sus encantos. Este centro compensa la densidad construida del entorno. ARQ

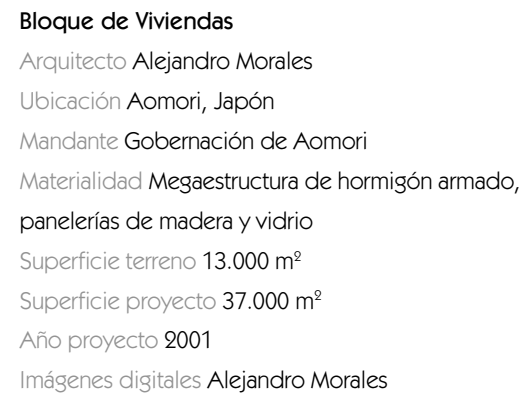

Imásenes digitales Alejandro Morales 